\title{
PENGARUH ERP TERHADAP PERBAIKAN PELAYANAN WAKTU TUNGGU DAN WAKTU TEMPUH TRANSJAKARTA PADA RUAS JALAN SUDIRMAN-THAMRIN
}

\author{
Lorenzo Adiel Giovanni ${ }^{1}$ dan Najid ${ }^{2}$ \\ ${ }^{1}$ Program Studi Sarjana Teknik Sipil, Universitas Tarumanagara, Jl. Letjen S. Parman No.1 Jakarta \\ Lorenzo.325150066@stu.untar.ac.id \\ ${ }^{2}$ Program Studi Sarjana Teknik Sipil, Universitas Tarumanagara, Jl. Letjen S. Parman No.1 Jakarta \\ najid@ft.untar.ac.id
}

Masuk: 02-07-2020, revisi: 03-09-2020, diterima untuk diterbitkan: 22-10-2020

\begin{abstract}
Transjakarta is one of the public transportation facility provided by Indonesian government as a solution to decrease traffic problem, now the government plans to implement new traffic rules, Electronic Road Pricing. This study will focus on Jl. Jendral Sudirman and Jl. MH. Thamrin, this road is an access to offices and tourist attractions. To analyze vehicle volume, direct observation method will be used to get the volume, speed and traffic density. Direct observations were made by paying attention to private vehicles and heavy vehicles. With the observation data will get a graph of the relationship between speed and density that will be modified with questionnaire data. Questionnaire data is distributed to get the percentage of Transjakarta waiting time and travel time. It is expected that this analysis can find out the percentage of private vehicle users who will move to Transjakarta after the ERP implemented on the Sudirman and MH Thamrin street.
\end{abstract}

Keywords: Sudirman; Thamrin; Transjakarta; ERP; Model

\begin{abstract}
ABSTRAK
Transjakarta merupakan salah satu sarana transportasi umum yang diberikan pemerintah Indonesia sebagai solusi mengatasi kepadatan lalu lintas, namun untuk saat ini pemerintah berencana menerapkan aturan lalu lintas baru yaitu jalan berbayar atau Electronic Road Pricing. Pada penelitian ini, dibahas mengenai kondisi lalu lintas Jl. Jendral Sudirman dan Jl. MH. Thamrin, ruas jalan ini merupakan akses pengguna jalan untuk menuju perkantoran dan tempat wisata. Untuk menganalisa volume kendaraan akan digunakan metode observasi langsung untuk mendapatkan volume, kecepatan dan kepadatan lalu lintas. Observasi langsung dilakukan dengan memperhatikan kendaraan bermotor roda empat dan dua, serta kendaraan berat. Dengan data observasi akan didapat grafik hubungan antara kecepatan dan kedapatan yang akan dimodifikasi dengan data kuesioner. Data kuesioner disebar untuk mendapatkan persentase pelayanan waktu tunggu dan waktu tempuh bus Transjakarta, Diharapkan pada analisis ini dapat mengetahui presentase pengguna kendaraan pribadi yang akan beralih ke Transjakarta setelah diberlakukannya ERP di ruas jalan Jendral Sudirman dan MH. Thamrin.
\end{abstract}

Kata kunci: Sudirman; Thamrin; Transjakarta; ERP; Model

\section{PENDAHULUAN}

Indonesia merupakan negara dengan penduduk terbanyak ke-4 di dunia dan Jakarta sebagai ibukota dan pusat bisnis di Indonesia menempati posisi pertama yang memiliki jumlah penduduk dan aktivitas tertinggi, perkembangan kota Jakarta yang pesat dengan tingkat pertambahan penduduk yang cukup tinggi yaitu sekitar $0,73 \%$ /tahun dengan jumlah penduduk kota Jakarta sebesar 10.500 juta jiwa (BPS, 2019). Hal ini pula yang menyebabkan masyarakat dari luar daerah bahkan mancanegara melakukan urbanisasi ke Jakarta untuk menopang kehidupan mereka menjadi lebih sejahtera.

Keinginan masyarakat untuk bergerak dan kebutuhan mereka akan barang telah menciptakan kebutuhan akan transportasi. Masyarakat Jakarta umumnya menggunakan transportasi pribadi untuk berpindah dari satu tempat ke tempat lainnya sehingga kondisi lalu lintas jalan di Jakarta menjadi semakin padat dan hampir setiap hari diwarnai dengan beberapa titik kemacetan di jalan arteri hingga jalan lokal, bahkan kapasitas jalan sudah tidak mampu menahan arus lalu lintas karena pertambahan jumlah kendaraan bermotor yang semakin pesat. Inilah yang menjadi penyebab menurunnya tingkat pelayanan jalan. 
Saat ini, pemerintah kota dan pusat memiliki gagasan untuk melakukan manajemen lalu lintas di kota metropolitan ini yaitu dengan Electronic Road Pricing (ERP), metode ini merupakan cara yang diterapkan di Hongkong sejak awal tahun 1980 dan diadopsi oleh Singapura pada September 1998. ERP digunakan untuk tujuan tertentu yaitu untuk mengurangi angka kepadatan lalu lintas, mengurangi polusi, agar penduduk menggunakan transportasi umum, meningkatkan kecepatan dan menambah pendapatan di suatu daerah atau Negara.

Badan Pengelola Transportasi Jabodetabek (BPTJ) merupakan organisasi yang terus mendorong Pemerintah Provinsi DKI agar segera menerapkan Electronic Road Pricing. Rencananya ERP akan ada di sepanjang Jalan Jendral Sudirman dan Jalan MH Thamrin. Upaya lain yang sejak dulu sudah digunakan pemerintah untuk mengatasi kemacetan di ibu kota ini adalah dengan dibangunnya sarana dan pra-sarana angkutan umum yang memudahkan masyarakat salah satunya adalah Transjakarta.

Bus Transjakarta menjadi sarana transportasi yang sudah dikenal oleh banyak orang, dengan tarif yang cukup terjangkau yaitu sebesar Rp.3.500 masyarakat bisa bepergian dengan jarak yang dekat maupun jauh. Dengan beralih dari kendaraan pribadi ke angkutan umum, diharapkan polusi udara dan tingginya kepadatan lalu lintas juga dapat berkurang. Akan tetapi Bus Transjakarta ini juga memiliki kekurangan diantaranya fasilitas halte yang kurang memadai, kurangnya armada bus yang digunakan sehingga terjadi penumpukan penumpang sehingga membuat penumpang menjadi kurang nyaman serta kurangnya kesadaran dari pengguna kendaraan pribadi yang masuk ke jalur Bus Transjakarta dan menyebabkan jalur Bus Transjakarta menjadi tersendat.

Dari berbagai daerah di Jakarta, penulis memilih Jalan Sudirman-Thamin untuk diteliti karena jalan ini merupakan salah satu jalan utama yang menjadi pusat dari perkantoran dan bisnis sehingga memiliki mobilitas yang tinggi. Jalan Sudirman-Thamrin juga akan menjadi jalan pertama yang akan digunakan pemerintah sebagai uji coba penerapan Electronic Road Pricing (ERP).

\section{Transjakarta}

Gubernur DKI Jakarta pada periode 1997-2007, Sutiyoso, memiliki gagasan untuk membangun sarana transportasi dengan mempertimbangkan segi biaya, tingkat kemudahan mewujudkannya, tingkat keberhasilan maupun kapasitas angkutnya. Pilihannya tersebut jatuh pada pembangunan jalur khusus bus atau Bus Rapid Transit (BRT) yang kemudian dikenal sebagai Transjakarta. Transjakarta merupakan sebuah sistem transportasi Bus Rapid Transit (BRT) pertama di Asia Tenggara dan Selatan dengan jalur lintasan terpanjang di dunia (208 km).

Menurut Susilo, Hartanto, dan Leontan (2007), bus yang digunakan sebagai bus transjakarta pada umumnya adalah bus mercedes-benz dan hino dengan warna bus adalah merah dan kuning dan bahan bakar yang dipakai adalah biosolar. disbanding dengan bus lain, bus transjakarta mempunyai pintu yang terletak lebih tinggi sehingga hanya dapat ditumpangi dari halte khusus busway (shelter). Menerapkan sistem lipat otomatis yang dapat dikendalikan dari konsol yang ada di panel pengemudi, pintu tersebut terletak dibagian tengah kanan dan kiri.

Menurut Saksono, Darmaningtyas, dan Waro (2012) Sistem BRT ini didesain berdasarkan sistem TransMilenio di Bogota, Kolombia. Terhitung sejak 1 Februari 2004, Transjakarta resmi beroperasi. Mengapa Pemprov DKI memilih Transjakarta ini, yaitu dikarenakan biayanya jauh lebih murah dibandingkan dengan moda transportasi lainnya seperti monorel atau subway. Dilihat dari kapasitas angkutnya, Transjakarta memiliki daya angkut yang tinggi, bila ditopang dengan bus gandeng, dapat mengangkut 15.000-35.000 penumpang per jam/lajur/arah. Waktu pengerjaannya pun lebih cepat, untuk satu koridor dapat dikerjakan dalam tempo satu tahun. Berdasarkan keputusan Gubernur No. 110/2003 Transjakarta pada saat itu diputuskan berbentuk Badan Pengelola (BP), dengan beberapa ketntuan diantaranya Transjakarta dikelola secara non-struktural, menggunakan dana transfer, anggaran yang fleksibel, pendapatan yang dapat disetor, bertanggungjawab langsung ke Gubernur. Namun, pada 4 Mei 2006, Gubernur DKI Sutiyoso mengubah BP TransJakarta menjadi Badan Layanan Umum (BLU) Transjakarta yang adalah Unit Pelaksana Teknis (UPT) di bawah Dinas Perhubungan (Dishub) Provinsi DKI Jakarta. Hal ini diatur dalam Peraturan Gubernur (Pergub) DKI No. 48 Tahun 2006. Pada 27 Maret 2014, TransJakarta berubah status menjadi bentuk BUMD (Badan Usaha Milik Daerah) dan resmi berganti nama menjadi PT. Transportasi Jakarta. Rencana pembukaan layanan koridor-koridor baru terus berjalan dan inovasi-inovasi pun diluncurkan demi kenyamanan para pelanggan.

\section{Electronic road pricing (ERP)}

ERP merupakan pungutan yang dilakukan untuk mengurangi kemacetan lalu lintas, ERP diberlakukan kepada seluruh pengguna jalan agar membatasi jumlah kendaraan yang melewati kawasan tertentu. Singapura menjadi negara yang pertama sekali menerapkan Road Pricing yang diawali pada tanggal 2 Juni 1975 dengan Area Licening Scheme (ALS). 
Menurut Susantono (2008) Kebijakan Travel Demand Management dapat dibagi menjadi tiga group, yaitu: instrumen-instrumen regulasi (regulation instruments), persetujuan-persetujuan kerjasama (cooperative agreements), dan instrumen-instrumen ekonomi (economic instruments).

\section{Kapasitas jalan lalu lintas}

Menurut Abubakar (2012), kapasitas jalan merupakan efisiensi ruas jalan yang sempurna dalam satuan waktu tertentu untuk menangkal arus atau volume lalu lintas, dalam satuan jam (kend/jam) yang dinyatakan dalam jumlah kendaraan yang melewati potongan jalan tertentu atau dengan memperhitungkan berbagai jenis kendaraan yang melalui suatu jalan di gunakan satuan mobil penumpang sebagai satuan kendaraan dalam perhitungan kapasitas maka kapasitas menggunakan satuan mobil penumpang per jam atau (smp)/jam.

Ketika arus rendah kecepatan arus lalu lintas kendaraan bebas, tidak ada hambatan dari kendaraan lain, kapasitas terjadi ketika semakin banyak kendaraan yang melewati ruas jalan kecepatan akan semakin turun hingga suatu saat tidak bisa lagi arus atau volume lalu lintas bertambah. Kemudian dalam keadaan arus yang dipaksakan hingga suatu saat kondisi macet total arus akan berkurang terus, arus tidak bergerak dan kepadatan tinggi sehingga menyebabkan kemacetan.

\section{Hubungan volume dengan kecepatan dan kepadatan}

Menurut Rompis dan Jansen (2019), volume lalu lintas adalah hubungan antara kendaraan, jalan dan pengemudi. Pada kondisi yang sama tidak ada volume lalu lintas yang serupa, sehingga selalu beraneka ragam arus pada suatu ruas jalan tertentu.

Hubungan antara arus volume lalu lintas kecepatan dengan kepadatan lalu lintas dapat dilihat pada gambar sebagai berikut:

1. Hubungan antara kecepatan dengan arus

Hubungan antara kecepatan dengan arus yaitu parabola yang menyajikan bahwa semakin besar arus, kecepatan akan turun sampai suatu titik yang menjadi puncak parabola tercapai kinerja setelah itu kecepatan akan semakin rendah lagi dan arus juga akan semakin kecil dapat dilihat pada gambar 1.

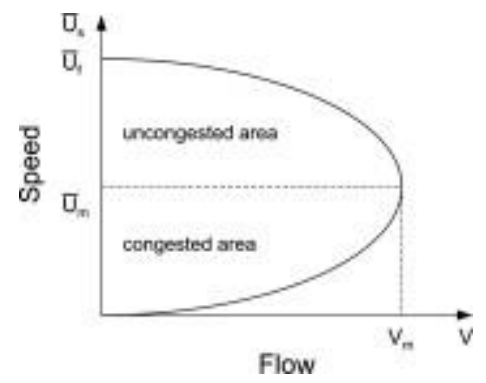

Gambar 1. Hubungan antara arus dengaan kecepatan (Sumber: Manual Kapasitas Jalan Indonesia, 1997)

2. Hubungan antara kecepatan dengan kepadatan

Hubungan antara kecepatan dengan kepadatan merupakan linear yang dapat diartikan bahwa semakin tinggi kecepatan lalu lintas, maka diperlukan ruang bebas yang lebih besar antara kendaraan, yang menyebabkan menjadi lebih kecil jumlah kendaraan perkilometer dapat dilihat pada gambar 2.

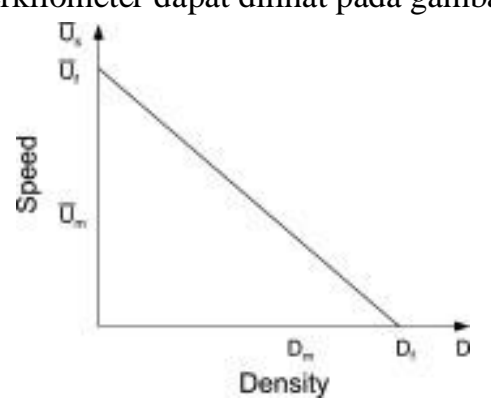

Gambar 2. Hubungan antara kecepatan dengan kepadatan (Sumber: Manual Kapasitas Jalan Indonesia, 1997) 

dan Waktu Tempuh Transjakarta pada Ruas Jalan SudirmanThamrin

3. Hubungan antara volume dengan kepadatan

Hubungan antara volume dengan lalu lintas juga parabolik yaitu semakin tinggi kepadatan sampai pada titik dimana kapasitas terjadi serta semakin padat maka arus akan semakin kecil dapat dilihat pada gambar 3.

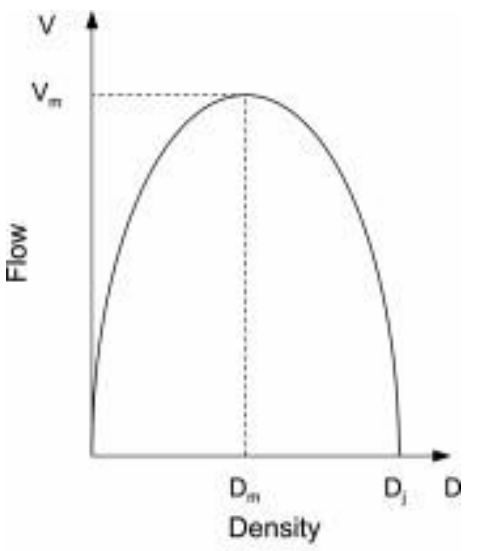

Gambar 3. Hubungan antara arus dengan kepadatan (Sumber: Manual Kapasitas Jalan Indonesia, 1997)

\section{METODE PENELITIAN}

Pada penelitian ini, harus dibuat jalannya penelitian yang akan menjadi panduan dalam pelaksanaan penelitian agar penelitian dapat dijalankan dengan baik dan sistematis. Awal penelitian akan dilakukan pengamatan secara langsung di tempat, penyebaran kuesioner dengan kuesioner berjenis stated preference serta akan dilakukan pengamatan secara langsung di tempat, penyebaran kuesioner dengan ataupun wawancara langsung dengan narasumber. Angka penggunaan kendaraan akan diperhitungkan dan dibuat modelnya, lalu akan dibuat dalam grafik hubungan antara kecepatan, kepadatan, dan volume. Kemudian akan diidentifikasi masalah yang telah ada, lalu akan dilakukan pembuatan formulir survei yang akan di uji coba terlebih dahulu sebelum formulir survei sebagai kuesioner akhir.

Pengambilan data yang akan diambil yaitu data primer. Dimana data primer yaitu data hasil pengamatan dan hasil dari penyebaran kuesioner dan wawancara. Dari data primer ini akan dibuat model transportasinya yaitu dari data hasil pengamatan dan kemudian akan di modifikasi dengan menggunakan hasil data kuesioner yang akan dibuat kembali model transportasinya. Pengambilan data hasil pengamatan akan didapatkan kecepatan, kepadatan, dan volume kendaraan. Pengambilan data kuesioner akan didapatkan jumlah pengguna Transjakarta yang sebelumnya menggunakan kendaraan pribadi dan kepuasan mereka terhadap pelayanan bus tersebut, serta pengaruh ERP terhadap permintaan penumpang Transjakarta.

Setelah menyelesaikan semua penelitian hingga akhir, dapat mendapatkan model lalu lintas serta hubungan kinerja lalu lintas dengan permintaan Transjakarta pada ruas jalan Sudirman-Thamrin.

Metode yang akan digunakan dalam penulisan ini yaitu:

1. Studi literatur atau perpustakaan, dengan sumber seperti buku, jurnal- jurnal ilmiah yang ada hubungannya dengan yang akan dibahas, artikel - artikel yang ada di internet dan sebagainya.

2. Pendekatan metode survei.

3. Metode survei pada jalan yang ditinjau dengan cara memperhatikan jumlah kendaraan yang lewat dalam kurun waktu kurang lebih 1 jam.

4. Menganalisis data pengamatan dengan membuat model transportasi dan grafik hubungan antara kecepatan, kepadatan, dan volume.

5. Menganalisis data kuesioner.

\section{Metode pengumpulan data}

Survei yang akan dilakukan dengan cara pengamatan langsung ditempat adalah salah satu metode primer dalam penelitian ini yang mencangkup banyak hal seperti kapasitas jalan, kecepatan rata - rata, volume lalu lintas, dan tingkat kepuasan pelayanan Transjakarta diruas jalan Sudirman-Thamrin. Selain pengamatan secara langsung, survei ini didukung juga dengan survei wawancara atau kuesioner yang dimana hasil dari kuesioner ini akan digunakan untuk memodifikasi hasil survei pengamatan. 


\section{Metode wawancara kuesioner}

Menurut P.Joko Subagyo (2011) wawancara adalah suatu kegiatan dilakukan untuk mendapatkan informasi secara langsung dengan mengungkapkan pertanyaan-pertanyaan pada para responden. Karena tidak mungkin menggunakan wawancara pada 1000 responden wawancara penelitian sampel besar umumnya hanya dilakukan sebagai studi pendahuluan, sebaliknya dapat diterapkan sebagai teknik pengumpulan data (umumnya penelitian kualitatif) pada sampel kecil teknik wawancara. Ada dua jenis wawancara, yaitu sebagai berikut:

1. Wawancara terstruktur yaitu dapat diartikan bahwa peneliti telah mengetahui yakni apa informasi yang ingin digali dari responden sehingga pertanyaannya sudah dibuat secara terstruktur. Peneliti juga dapat dibantu dengan menggunakan alat bantu tape recorder, kamera photo dan material lain yang agar memudahkan dalam kelancaran wawancara.

2. Wawancara tidak terstruktur atau wawancara bebas, yaitu dari responden peneliti hanya menampung poin-poin penting masalah yang ingin digali tidak menggunakan dasar-dasar wawancara yang berisi pertanyaan yang akan diajukan secara spesifik.

Kuesioner adalah teknik pengumpulan data yaitu dengan cara memberikan seperangkat pernyataan atau pertanyaan kepada orang yang dijadikan responden untuk dijawabnya. Meskipun terlihat mudah, teknik pengumpulan data melalui kuesioner cukup sulit dilakukan jika respondennya cukup besar dan tersebar di beragam wilayah. Beberapa hal yang perlu diperhatikan dalam pembuatan kuesioner terkait dengan prinsip penulisan kuesioner, prinsip pengukuran dan penampilan fisik.

1. Isi dan tujuan pertanyaan yakni harus ada skala yang jelas dalam pilihan jawaban jika pertanyaan ditunjukan untuk memperkirakan.

2. Bahasa yang digunakan harus disesuaikan dengan kesanggupan responden. Tidak mungkin menggunakan bahasa yang penuh sebutan-sebutan bahasa inggris pada responden yang tidak paham Bahasa Inggris dan sebagainya.

3. Jika tipe dan bentuk pertanyaan terbuka artinya jawaban yang diberikan adalah bebas, sedangkan jika pertanyaan tertutup maka responden hanya diminta untuk memilih jawaban yang disediakan.

\section{Metode regresi linear berganda}

Regresi linear adalah metode statistika yang digunakan untuk membuat model hubungan antara variabel terikat (dependen; responden; Y) dengan satu atau lebih variabel bebas (independen; prediktor; X). Analisis regresi setidaknya memiliki 3 kegunaan, yaitu untuk tujuan deskripsi dari fenomena data atau kasus yang sedang diteliti, untuk tujuan pengamatan, serta untuk tujuan prediksi.

Dari variabel-variabel bebas yang digunakan untuk membentuk model regresi tersebut, bentuk persamaan regresi linear sebagai berikut:

$$
\begin{aligned}
& b=\frac{\left(n \cdot \sum x y\right)-\left(\sum x \cdot \sum y\right)}{\left(n \cdot \sum x^{2}\right)-\left(\sum x \cdot \sum y\right)} \\
& a=\frac{\sum y}{n}-\frac{b \cdot \sum x}{n} \\
& Y=a+b \cdot X
\end{aligned}
$$

dengan $\mathrm{Y}=$ variabel hasil prediksi, $\mathrm{a}=$ konstanta kurva linear, $\mathrm{b}=$ koefisien parameter laju, $\mathrm{X}=$ pertumbuhan beban variabel, dan $\mathrm{n}$ : jumlah data

Regresi linear sederhana yaitu Jika banyaknya variabel bebas hanya ada satu, sedangkan regresi linear berganda yaitu apabila terdapat lebih dari 1 variabel bebas. Analisis ini untuk mendapatkan arah hubungan antara variabel independen dengan variabel dependen apakah masing-masing variabel independen berhubungan positif atau negatif dan untuk memprediksi nilai dari variabel dependen apabila nilai variabel independen mengalami kenaikan atau penurunan. Data yang digunakan biasanya berskala interval atau rasio. (Regresi)

Persamaan linear berganda, yaitu sebagai berikut:

$$
\mathrm{Y}^{\prime}=\mathrm{A}+\mathrm{b}_{1} \mathrm{X}_{1}+\mathrm{b}_{2} \mathrm{X}_{2}+\ldots .+\mathrm{b}_{\mathrm{n}} \mathrm{X}_{\mathrm{n}}
$$

dengan $Y^{\prime}=$ Variabel dependen (nilai yang diprediksi), $X_{1}$ dan $X_{2}=$ Variabel independent, $a=$ Konstanta (nilai $Y^{\prime}$ apabila $X_{1}, X_{2}, \ldots . . X_{n}=0$ ), dan $b=$ koefisien regresi (nilai peningkatan ataupun penurunan) 

dan Waktu Tempuh Transjakarta pada Ruas Jalan SudirmanThamrin

\section{HASIL DAN PEMBAHASAN}

\section{Tabulasi data}

Pada bab ini akan menyajikan data yang diperoleh dari kuesioner responden yang disebar kepada responden pengguna Transjakarta dan kendaraan pribadi di daerah Sudirman-Thamrin yang disurvei melalui online. Data responden yang diambil sebanyak 50 orang. Data responden didapatkan dengan cara menyampaikan kuesioner secara langsung. Tabulasi data perbaikan waktu tempuh Transjakarta dapat dilihat pada tabel 1, yaitu sebagai berikut:

Tabel 1. Tabulasi data kuesioner

\begin{tabular}{|c|c|c|c|c|c|}
\hline No & Kondisi Pelayanan Transjakarta & 1 & 2 & 3 & 4 \\
\hline 1 & $\begin{array}{l}\text { Waktu tunggu di halte Transjakarta lebih cepat } 5 \text { menit, Waktu } \\
\text { tempuh lebih cepat } 25 \text { menit. }\end{array}$ & 10 & 25 & 27 & 5 \\
\hline 2 & $\begin{array}{l}\text { Waktu tunggu di halte Transjakarta lebih cepat } 10 \text { menit, Waktu } \\
\text { tempuh lebih cepat } 20 \text { menit. (pelayanan lainnya sama dengan } \\
\text { kondisi saat ini) }\end{array}$ & 4 & 16 & 41 & 6 \\
\hline 3 & $\begin{array}{l}\text { Waktu tunggu di halte Transjakarta lebih cepat } 15 \text { menit, waktu } \\
\text { tempuh lebih cepat } 15 \text { menit. (pelayanan lainnya sama dengan } \\
\text { kondisi saat ini) }\end{array}$ & 4 & 17 & 31 & 15 \\
\hline
\end{tabular}

\section{Keterangan: \\ 1. Sangat Tidak Setuju \\ 2. Kurang Setuju \\ 3. Setuju \\ 4. Sangat Setuju}

Lokasi jalan untuk survei lalu lintas yaitu Jalan M.H Thamrin (Depan Mall Plaza Indonesia sampai Bank Indonesia) serta Jalan Jendral Sudirman (Karet sampai Gelora Bung Karno). Lokasi ini dipilih karena merupakan salah satu lokasi yang memiliki angka kepadatan yang cukup tinggi dan dilewati oleh moda transportasi Umum, Transjakarta. Dengan adanya moda transportasi seperti Transjakarta ditargetkan untuk menjadi lokasi untuk program Electronic Road Pricing (ERP) dan diharapkan angka kepadatan lalu lintas berkurang setelah program tersebut diberlakukan. Kapasitas Jalan arah Thamrin - Sudirman dapat dilihat pada tabel 2, sebagai berikut:

Tabel 2. Kapasitas jalan arah Thamrin - Sudirman

\begin{tabular}{ccccccccc}
\hline Waktu & Jarak & $\begin{array}{c}\text { Kendaraan tidak } \\
\text { bermotor }\end{array}$ & $\begin{array}{c}\text { Pejalan } \\
\text { kaki }\end{array}$ & $\begin{array}{c}\text { Keluar } \\
\text { masuk }\end{array}$ & Parkir & Hambatan & $\begin{array}{c}\text { Kelas } \\
\text { Hambatan }\end{array}$ & C \\
\hline $06.00-08.00$ & 200 & 5 & 49 & 13 & 2 & 37.6 & VL & 4223.7 \\
\hline $12.00-14.00$ & 200 & 7 & 64 & 11 & 5 & 47.5 & VL & 4223.7 \\
\hline $17.00-19.00$ & 200 & 3 & 61 & 19 & 4 & 49 & VL & 4223.7 \\
\hline
\end{tabular}

Data aspek transportasi yang disurvei di lapangan adalah kondisi lalu lintas, kecepatan rata - rata lalu lintas, jalur, lajur, lebar jalan, lebar trotoar dan hambatan samping. Kemudian dilakukan analisis terhadap jalan Analisis Ruas Jalan Thamrin arah Thamrin - Sudirman yang dapat dilihat pada tabel 3, tabel 4, dan tabel 5 berikut ini: 
Tabel 3. Analisis Ruas Jalan Thamrin arah Thamrin - Sudirman (06.00 - 07.00)

\begin{tabular}{|c|c|c|c|c|c|c|c|c|c|c|c|}
\hline \multirow[b]{2}{*}{ Waktu } & \multirow{2}{*}{$\begin{array}{c}\text { Jarak } \\
(\mathrm{m})\end{array}$} & \multicolumn{2}{|c|}{ Motor } & \multicolumn{2}{|c|}{ Mobil } & \multirow{2}{*}{$\begin{array}{c}\text { Bus/Truk } \\
\text { Total }\end{array}$} & \multicolumn{2}{|c|}{$\mathrm{V}$} & \multirow{2}{*}{ Q } & \multirow[b]{2}{*}{ V } & \multirow[b]{2}{*}{$\mathrm{Q} / \mathrm{V}$} \\
\hline & & Total & $\begin{array}{l}\mathrm{T} \\
(\mathrm{s})\end{array}$ & Total & $\begin{array}{l}\mathrm{T} \\
(\mathrm{s})\end{array}$ & & Motor & $\begin{array}{l}\text { Roda } \\
\text { Empat }\end{array}$ & & & \\
\hline $\begin{array}{c}06.00- \\
06.15\end{array}$ & 200 & 970 & 18 & 566 & 20 & 6 & 40 & 36 & 1542 & 38 & 40,5789 \\
\hline $\begin{array}{c}06.15- \\
06.30\end{array}$ & 200 & 955 & 18 & 479 & 21 & 7 & 40 & 34,2857 & 1441 & 37,1428 & 38,7961 \\
\hline $\begin{array}{c}06.30- \\
06.45\end{array}$ & 200 & 985 & 18 & 551 & 21 & 8 & 40 & 34,2857 & 1544 & 37,1428 & 41,5692 \\
\hline $\begin{array}{c}06.45- \\
07.00\end{array}$ & 200 & 934 & 19 & 599 & 22 & 5 & 37.89 & 32,7272 & 1538 & 33,311 & 43,5558 \\
\hline
\end{tabular}

Tabel 4. Analisis Ruas Jalan Thamrin arah Thamrin - Sudirman (12.30 - 13.30)

\begin{tabular}{|c|c|c|c|c|c|c|c|c|c|c|c|}
\hline \multirow[b]{2}{*}{ Waktu } & \multirow{2}{*}{$\begin{array}{c}\text { Jarak } \\
(\mathrm{m})\end{array}$} & \multicolumn{2}{|c|}{ Motor } & \multicolumn{2}{|c|}{ Mobil } & \multirow{2}{*}{$\begin{array}{c}\text { Bus/Truk } \\
\text { Total }\end{array}$} & \multicolumn{2}{|c|}{$\mathrm{V}$} & \multirow{2}{*}{ Q } & \multirow[b]{2}{*}{$\mathrm{V}$} & \multirow[b]{2}{*}{$\mathrm{Q} / \mathrm{V}$} \\
\hline & & Total & $\mathrm{T}(\mathrm{s})$ & Total & $\mathrm{T}(\mathrm{s})$ & & Motor & $\begin{array}{c}\text { Roda } \\
\text { Empat }\end{array}$ & & & \\
\hline $\begin{array}{c}12.30- \\
12.45\end{array}$ & 200 & 1023 & 19 & 557 & 23 & 5 & 37,89 & 31,3043 & 1585 & 34,5995 & 45,8098 \\
\hline $\begin{array}{c}12.45- \\
13.00\end{array}$ & 200 & 1003 & 20 & 526 & 24 & 2 & 36 & 30 & 1531 & 33 & 46,3939 \\
\hline $\begin{array}{c}13.00- \\
13.15\end{array}$ & 200 & 1127 & 19 & 498 & 23 & 2 & 37,89 & 31,3043 & 1627 & 34,5995 & 47,0237 \\
\hline $\begin{array}{c}13.15- \\
13.30\end{array}$ & 200 & 1201 & 20 & 495 & 23 & 5 & 36 & 31,3043 & 1701 & 33,6521 & 50,5465 \\
\hline
\end{tabular}

Tabel 5. Analisis Ruas Jalan Thamrin arah Thamrin - Sudirman (17.00 - 18.00)

\begin{tabular}{|c|c|c|c|c|c|c|c|c|c|c|c|}
\hline \multirow[b]{2}{*}{ Waktu } & \multirow{2}{*}{$\begin{array}{c}\text { Jarak } \\
(\mathrm{m})\end{array}$} & \multicolumn{2}{|c|}{ Motor } & \multicolumn{2}{|c|}{ Mobil } & \multirow{2}{*}{$\begin{array}{c}\text { Bus/Truck } \\
\text { Total }\end{array}$} & \multicolumn{2}{|c|}{ V } & \multirow[b]{2}{*}{ Q } & \multirow[b]{2}{*}{$\mathrm{V}$} & \multirow[b]{2}{*}{$\mathrm{Q} / \mathrm{V}$} \\
\hline & & Total & $\begin{array}{l}\mathrm{T} \\
(\mathrm{s})\end{array}$ & Total & $\begin{array}{l}\mathrm{T} \\
(\mathrm{s})\end{array}$ & & Motor & $\begin{array}{l}\text { Roda } \\
\text { Empat }\end{array}$ & & & \\
\hline $\begin{array}{c}17.00- \\
17.15\end{array}$ & 200 & 930 & 18 & 499 & 25 & 8 & 40 & 28,8 & 1437 & 34,4 & 41,7732 \\
\hline $\begin{array}{c}17.15- \\
17.30\end{array}$ & 200 & 943 & 17 & 539 & 25 & 2 & 42.35 & 28,8 & 1484 & 35,5764 & 41,7129 \\
\hline $\begin{array}{c}17.30- \\
17.45\end{array}$ & 200 & 915 & 17 & 529 & 26 & 3 & 42.35 & 27,6923 & 1447 & 35,0226 & 41,3161 \\
\hline $\begin{array}{c}17.45- \\
18.00\end{array}$ & 200 & 907 & 20 & 542 & 29 & 1 & 36 & 24,8275 & 1450 & 30,4137 & 47,6757 \\
\hline
\end{tabular}

\section{Analisis kuisioner presepsi responden terhadap pilihan bus transjakarta sebagai alternatif pengganti kendaraan pribadi}

Dari kuesioner yang telah dihitung menggunakan analisa statistik metode regresi didapatkan persamaan sebagai berikut:

$$
\mathrm{Y}=0,00001-0,229 \cdot \mathrm{X} 1-0,0203 . \mathrm{X} 2
$$


Thamrin

Variabel X1 menunjukkan peningkatan pelayanan Transjakarta dengan memperkecil waktu tunggu sedangkan variabel X2 menunjukkan peningkatan pelayanan Transjakarta dengan memperkecil waktu tempuh. Hasil pemodelan waktu tunggu dan waktu tempuh dapat dilihat pada tabel 6.

Tabel 6. Tabel pemodelan

\begin{tabular}{cccc}
\hline \multicolumn{4}{c}{$\mathrm{Y}=0,00001-0,229 . \mathrm{X} 1-0,0203 . \mathrm{X} 2$} \\
\hline $\mathrm{Y} 1$ & $\mathrm{X} 1$ & $\mathrm{X} 2$ & $\mathrm{Y}$ \\
\hline 0,00001 & -5 & -25 & 1,65251 \\
\hline 0,00001 & -10 & -20 & 2,69601 \\
\hline 0,00001 & -15 & -15 & 3,73951 \\
\hline 0,00001 & -10 & -25 & 2,79751 \\
\hline 0,00001 & -15 & -25 & 3,94251 \\
\hline
\end{tabular}

Dari hasil yang diperhitungkan dan analisis yang telah dilakukan, maka diperoleh sebagai berikut:

1. Dari hasil jawaban data kuesioner dapat disimpulkan bahwa waktu tunggu lebih cepat 10 menit dan waktu tempuh lebih cepat 20 menit merupakan waktu yang diminati oleh responden karena sebanyak 41 responden memilih waktu pelayanan tersebut.

2. Dari hasil analisis data dapat dilihat pada masing - masing ruas jalan mengalami kenaikan kecepatan dan volume kendaraan yang tinggi mengalami pengurangan.

3. Dari hasil pengujian model regresi linier dapat dilihat bahwa X1 dan X2 berpengaruh kepada Y, hal ini menandakan bahwa waktu tunggu lebih cepat 15 menit dan waktu tempuh lebih cepat 25 menit merupakan waktu yang efisien untuk pelayanan bus Transjakarta.

\section{Analisis Electronic Road Pricing dan grafik hubungan antara kecepatan kepadatan}

Berdasarkan penelitian yang telah dilakukan dan diuji sebelumnya. Kuesioner mengenai Electronic Road Pricing yang telah dimasukan kedalam program SPSS dengan menggunakan analisis regresi linear didapatkan persamaan sebagai berikut:

Perp $=0,887+0,017 \mathrm{X} 1-0,035 \mathrm{X} 2$

Pada analisis ini akan diketahui nilai penurunan $\mathrm{Q} / \mathrm{V}$ dalam persen dan akan dimasukan kedalam grafik hubungan kecepatan dan kepadatan. Variabel X1 menunjukkan harga dan variabel X2 menunjukan waktu. Perp yang bernilai 1 akan memiliki koefisien sebesar 1, bila bernilai 2 akan memiliki koefisien sebesar 0,8, bila bernilai 3 akan memiliki koefisien sebesar 0,5, dan bila bernilai 4 akan memiliki koefisien sebesar 0,2. Nilai koefisien akan diinterpolasi bila memiliki nilai yang tidak bulat. Hasil pemodelan analisis Electronic Road Pricing dapat dilihat pada tabel 7 (Tabel Perp).

Tabel 7. Tabel Perp

\begin{tabular}{|c|c|c|c|c|}
\hline \multicolumn{4}{|c|}{ Perp $=0,887+0,017 \mathrm{X} 1-0,035 \mathrm{X} 2$} & \multirow{2}{*}{ Koef } \\
\hline$Y$ & $\mathrm{X} 1$ & $\mathrm{X} 2$ & Perp & \\
\hline 0,887 & 15 & 10 & 1,492 & 0,2984 \\
\hline 0,887 & 30 & 20 & 2,097 & 0,4194 \\
\hline 0,887 & 40 & 30 & 2,617 & 0,5234 \\
\hline 0,887 & 50 & 40 & 3,137 & 0,6274 \\
\hline 0,887 & 60 & 45 & 3,482 & 0,6964 \\
\hline 0,887 & 65 & 50 & 3,742 & 0,7484 \\
\hline
\end{tabular}


Koefisien yang didapat akan dikalikan dengan Q/V pada grafik hubungan kecepatan dan kepadatan pada ruas jalan yang telah dibuat sebelumnya. Pada permodelan ini akan hanya menyajikan ERP dengan harga 15.000, 30.000, dan 40,000. Ini dikarenakan responden lebih banyak memilih pilihan harga tersebut. Hasil perbandingan kepadatan, kecepatan dan volume dengan rekayasa ERP dapat dilihat pada Tabel 8.

Tabel 8. Perbandingan kepadatan, kecepatan dan volume dengan rekayasa ERP pada Ruas Jalan Thamrin Sudirman

\begin{tabular}{ccccccc}
\hline Harga & D awal & V awal & Volume awal & D erp & V erp & Volume erp \\
\hline \multirow{3}{*}{15.000} & 38,3158 & 38 & 1456 & 34,5455 & 39,4539 & 1362,954648 \\
\cline { 2 - 7 } & 44,7093 & 34,4 & 1538 & 40,3099 & 36,7538 & 1481,543854 \\
\cline { 2 - 7 } & 50,5465 & 33,6522 & 1701 & 45,5727 & 34,2887 & 1562,631246 \\
\hline \multirow{3}{*}{30.000} & 38,3158 & 38 & 1456 & 29,5376 & 41,7996 & 1234,660693 \\
\cline { 2 - 7 } & 44,7093 & 34,4 & 1538 & 34,4664 & 39,4909 & 1361,110501 \\
\cline { 2 - 7 } & 50,5465 & 33,6522 & 1701 & 38,9663 & 37,3832 & 1456,684516 \\
\hline \multirow{2}{*}{45.000} & 38,3158 & 38 & 1456 & 23,5604 & 44,5993 & 1050,776845 \\
\cline { 2 - 7 } & 44,7093 & 34,4 & 1538 & 27,4918 & 42,7579 & 1175,488516 \\
\hline
\end{tabular}

\section{KESIMPULAN DAN SARAN}

\section{Kesimpulan}

Berdasarkan penelitian yang telah dilakukan, maka diperoleh beberapa kesimpulan berikut:

1. Dari hasil pengamatan pada ruas jalan Sudirman dan Thamrin, diketahui bahwa peningkatan volume kendaraan terjadi pada pagi hari (Pukul 06.00-08.00) dan pada sore hari (17.00-19.00). Hal ini dikarenakan pengguna jalan lebih banyak disaat jam berangkat dan pulang kerja.

2. Dari hasil kuisioner yang telah disebar dapat diketahui bahwa responden lebih cenderung memilih waktu efisien pelayanan bus Transjakarta yaitu mempercepat waktu tunggu hingga 10 menit dan mempercepat waktu tempuh hingga 20 menit setelah ERP diterapkan.

3. Dari hasil analisis yang sudah dihitung dapat disimpulkan bahwa mepercepat waktu tunggu hingga 15 menit dan waktu tempuh hingga 25 menit merupakan waktu yang efektif agar pengguna kendaraan pribadi memilih menggunakan bus Transjakarta setelah diterapkannya ERP. Selain dari analisis, hasil kuisioner juga berpengaruh dalam kesimpulan ini

\section{Saran}

Berdasarkan penelitian yang telah dilakukan, maka diperoleh beberapa saran sebagai berikut:

1. Penelitian yang sama perlu diberlakukan pada beberapa ruas jalan besar yang saat ini diterapkan ganjil-genap dan dilalui bus Transjakarta.

2. Untuk penelitian selanjutnya dapat dilakukan di berbagai kondisi untuk melihat perbedaan keefektifan dalam penggunaan transportasi bus Transjakarta.

\section{DAFTAR PUSTAKA}

Abubakar, Iskandar. "Manajemen Lalu Lintas". jakarta: TRANSINDO Gastama Media, 2012.

Direktorat Jendral Bina Marga. "Manual Kapasitas Jalan Indonesia". 1997.

P.Joko Subagyo ."Metodologi Penelitian Dalam Teori Dan Praktek." Jakarta: Aneka Cipta, 2011.

Rompis, Semuel Y.R. dan Freddy Jansen. "Pengaruh Penerapan Road Pricing Pada Ruas Jalan”. Sipil Statik (2019): 103-112. Web. 23 Juni. 2020.

Saksono, Bani, Darmaningtyas dan Achmad Izzul Waro. Manajemen Transjakarta Busway. Jakarta: Transindo Gastama Media, 2012. 
Pengaruh ERP terhadap Perbaikan Pelayanan Waktu Tunggu

Lorenzo Adiel Giovanni, et al. dan Waktu Tempuh Transjakarta pada Ruas Jalan Sudirman-

Thamrin

Susantono, Bambang. "Electronic Road Pricing (ERP) Salah Satu Solusi Masalah Kemacetan di Kota Jakarta". Jakarta: Buletin Tata Ruang, 2008. Web. 26 Februari. 2020.

Susilo, Budi Hartanto dan Apriyanto Leontan. "Kajian Operasi Bus Rapid Transit Transjakarta dan Transmilenio Bogota”. (2007). Web 21 Juni. 2020. 